\section{FACULTADES DE LAS VÍCTIMAS COMO SUJETOS PROCESALES EN EL SISTEMA ACUSATORIO DE CONFOR- MIDAD CON LA JURISPRUDENCIA DE LA CORTE CONSTITUCIONAL*}

\author{
Alvaro E. Márquez Cárdenas ${ }^{* *}$ \\ Universidad Militar Nueva Granada
}

Fecha de recepción: 20 de abril de 2009

Fecha de aceptación: 11 de mayo de 2009

\section{Resumen}

La Corte Constitucional desde la vigencia de la Ley 906 de 2004, ha venido consolidando y reconociendo los derechos de las víctimas en el proceso penal de tendencia acusatoria. En el presente escrito, pretendemos señalar con fundamento en esos derechos, las facultades y oportunidades procesales que tienen las víctimas y los perjudicados como sujetos procesales para actuar y participar activamente en la investigación y el juicio en defensa de sus derechos.

\section{Palabras clave}

Víctima, compensación, indemnización, autores, sujetos procesales, daño, perjuicio, derechos, verdad, impunidad, reparación.

\section{POWERS OF THE VICTIM AS A SUBJECT IN THE PROCESS OF ACCUSATORY SISTEM IN ACCORDANCE WHITH THE JURISPRUDENCE OF THE CONSTITUTIONAL COURT}

\footnotetext{
Abstract

The Constitutional Court since the existence of Act 906 of 2004, has been consolidating, and

El presente escrito es el resultado de la investigación denominada: La Conciliación preprocesal en el nuevo sistema procesal acusatorio. Línea de investigación: Derecho penal. Centro de investigaciones de la Universidad Militar Nueva Granada

** Abogado. Doctor en Derecho. Universidad Complutense de Madrid, España. Estudios de postdoctorado Universidad Carlos II de Madrid. Especialista en criminología. Instituto de criminología, U. Complutense. Master en Estudios Políticos, Universidad Javeriana, ex magistrado, Docente investigador-postgrados de la Facultad de Derecho de la Universidad Militar. Investigador Centro de investigaciones de la Universidad Militar Nueva Granada.
}

recognizing the rights of victims in the trend of adversarial criminal proceedings. In this paper, we intend to draw on the basis of such rights, powers and procedural opportunities that are victims and injured persons to act as parties to the proceedings and actively participate in the investigation and trial in defense of their rights.

\section{Keywords}

Victim, compensation, indemnity, author, subject proceedings, damages, rights, truth, impunity repair.

\section{RESULTADOS}

El sistema de protección a la víctima en el ordenamiento procesal colombiano, es decir, en el sistema acusatorio, derivado del Acto Legislativo 003 del 19 de diciembre de 2003, ha suscitado un importante debate académico frente a su implementación y desarrollo en la ley 906 de 2004.

Aunque en nuestra legislación procesal de la ley 600 de 2000 la víctima no ha estado en marginación, pues, ella puede estar representada por un abogado, se reconoce una acción civil individual, pueden ejercer derecho de petición ante el funcionario judicial con el fin de obtener información o hacer solicitudes especificas, pueden aportar pruebas, pero además aparecen otras figuras, como el tercero civilmente responsable, o la denuncia del pleito o el llamamiento en garantía, que otorgan ciertas garantías a las víctimas a efectos de que sean indemnizadas por los perjuicios que se les hubieren ocasionado como consecuencia de la realización de una conducta punible y que, incluso, en el sistema procesal acusatorio no se consagran; por lo tanto, lo que con el ordenamiento procesal penal se debe buscar es mejorar el tratamiento de las mismas, sin que ello implique desmedro alguno para el autor o participe del delito ${ }^{1}$.

SANPEDRO ARRUBLA, Julio Andrés. "La reconstrucción victimológica del sistema penal: las víctimas del delito en la reforma constitucional de la justicia penal". En revista Reforma de la justicia penal, tomo II, Bogotá, Corporación excelencia de la Justicia, 2003. pág. 103 y ss. 
Un significativo avance en materia de víctimas en nuestro país se presentó con la Sentencia C228 de 2002 de la Corte Constitucional, en el sentido de reconocer que la víctima o perjudicado con un delito no solo tiene derecho a la reparación económica de los perjuicios, como venía ocurriendo frente a la parte civil, sino que además tiene derecho a que a través del proceso penal se establezca la verdad y se haga justicia.

Dijo al respecto la Corte Constitucional con ponencia del Dr. Manuel Cepeda y el Dr. Eduardo Montealegre:

“... los derechos de las víctimas y perjudicados por un hecho punible gozan de una concepción amplia no restringida exclusivamente a una reparación económica fundada en los derechos que ellas tienen a ser tratadas con dignidad, a participar en las decisiones que las afecten y a obtener la tutela judicial efectiva del goce real de sus derechos, entre otros, y que exige a las autoridades que orienten sus acciones hacia el restablecimiento integral de sus derechos cuando han sido vulnerados por un hecho punible. Ello solo es posible si a las víctimas y perjudicados por un delito se les garantizan, a lo menos, sus derechos a la verdad, a la justicia y a la reparación económica de los daños sufridos.

De tal manera que la víctima y los perjudicados por un delito tienen intereses adicionales a la mera reparación pecuniaria. Algunos de sus intereses han sido protegidos por la constitución de 1991 y se traducen en tres derechos relevantes para analizar la norma demandada en el presente proceso:

El derecho a la verdad, esto es, la posibilidad de conocer lo que sucedió y en buscar una coincidencia entre la verdad procesal y la verdad real. Este derecho resulta particularmente importante frente a graves violaciones de los derechos humanos.

El derecho a que se haga justicia en el caso concreto, es decir, el derecho a que no haya impunidad.
El derecho a la reparación del daño que se le ha causado a través de una compensación económica, que es la forma tradicional como se ha resarcido a la víctima del delito.

Aun cuando tradicionalmente la garantía de estos tres derechos le interesen a la parte civil, es posible que en ciertos casos, esta solo este interesada en el establecimiento de la verdad o el logro de la justicia y deje de lado la obtención de una indemnización...".

Esa tendencia de mayor protección a la víctima se vio reflejada en el Acto Legislativo 03 de 2002 que en su artículo $2^{\circ}$ modificó el artículo 250 de la Carta que consagra las funciones de la Fiscalía General de la Nación y que en sus numerales 1,6 y 7 dice textualmente:

1. Solicitar al juez que ejerza las funciones de control de garantías las medidas necesarias que aseguren la comparecencia de los imputados al proceso penal, la conservación de la prueba y la protección de la comunidad, en especial, de la víctimas.

2. Solicitar ante el juez de conocimiento las medidas judiciales necesarias para la asistencia a las víctimas, lo mismo que disponer el restablecimiento del derecho y la reparación integral a los afectados con el delito.

3. Velar por la protección de las víctimas, los jurados, los testigos y demás intervinientes en el proceso penal, la ley fijará los términos en que podrán intervenir las víctimas en el proceso penal y los mecanismos de justicia restaurativa.

Lo que pretende con el redescubrimiento es generar un equilibrio en la relación procesal, que así como se tiene en cuenta al procesado se tenga en cuenta los derechos y garantías de las víctimas del delito, permitiendo la redefinición de los roles que desarrollan las personas dentro del drama criminal y posteriormente en el proceso 
de la investigación penal ${ }^{2}$. Hay que cambiar el criterio según el cual los únicos protagonistas en proceso penal son el Estado y el delincuente; porque la víctima tiene mucho que decir, hacer y contribuir a la solución del conflicto penal. De esta manera las víctimas con voz propia y sin que nadie la sustituya son el camino obligado para la solución alternativa al proceso penal, adquiriendo la posición que les corresponde en la tragedia criminal.

Una vez reconocidos los derechos de la víctima en forma amplia por parte del Corte Constitucional, la jurisprudencia de esta alta Corporación inició con la sentencia C-454 de 2006, al determinar los alcances de las facultades de las víctimas para actuar en el proceso penal, así, se destaca la de solicitar pruebas en la audiencia preparatoria regulada en el artículo 357 de la Ley 906 de 2004 y destacó que la omisión del legislador al no incluir a las víctimas dentro de los actores procesales que podían hacer solicitudes probatorias en la audiencia preparatoria, era contraria a la Carta. Posteriormente en la sentencia C- 209 de 2007, dejó claro, que las víctimas no son meros intervinientes o sólo intervinientes especiales, sino verdaderos sujetos procesales o partes procesales con todos sus derechos en igualdad de condiciones o equivalentes a los que en el proceso acusatorio tiene el procesado, el fiscal o el ministerio público en su intervención procesal. En este acápite nos referimos a las facultades que, por vía jurisprudencial de la Corte Constitucional, se le han reconocido a las víctimas para participar en las audiencias públicas en todo el proceso penal y en especial en el debate probatorio, precisando también sus limitaciones en su intervención en el juicio oral.
2 Gaviria Londoño, Vicente Emilio. La víctima en el sistema acusatorio del nuevo Código de procedimiento penal. En revista Derecho penal y criminología. Volumen XXIV, Número 74, Enero-diciembre de 2003. Homenaje a Fernando Hinestrosa. Universidad Externado de Colombia. Bogotá, 2003. Pág. 93 y ss.

\section{FACULTADES DE LA VÍCTIMA PARA SOLICITAR MEDIDAS DE ASEGURAMIENTO Y DE PROTECCIÓN EN EL PROCESO PENAL}

En la sentencia C-805 de 2002, ${ }^{3}$ la Corte reconoció el derecho de las víctimas del delito a solicitar el control de legalidad de la decisión del fiscal de no imponer medidas de aseguramiento y en la sentencia C-209 de 2007, destacó la relevancia que tienen, para las víctimas, las determinaciones relacionadas con la imposición de medidas de aseguramiento al imputado y reconoció a las víctimas el derecho de controlar las omisiones, inacciones o decisiones que afecten sus derechos. En esa oportunidad expresó la Corte que la decisión de imponer la detención preventiva como medida de aseguramiento constituye un asunto de especial relevancia para la parte civil durante el proceso penal, por las siguientes razones:

a) Desde una perspectiva estrictamente patrimonial, es decir, atendiendo el interés resarcitorio de la parte civil, una determinación de esta naturaleza repercute en la posibilidad de solicitar el embargo y secuestro de bienes, dado que según el artículo 60 del

3 Corte Constitucional, Sentencia C-805 de 2002 MP. Manuel José Cepeda Espinosa y Eduardo Montealegre Lynett, salvamento de voto conjunto de Alfredo Beltrán Sierra y Álvaro Tafur Galvis. Ver la aclaración de voto del Magistrado Manuel José Cepeda Espinosa, a la sentencia C-456 de 2006, MP. Alfredo Beltrán Sierra -que declaró inexequible las expresiones "...por una sola vez" y "Contra esta decisión no procede recurso alguno.", contenidas en el artículo 318 de la Ley 906 de 2004, que regula la solicitud de revocatoria de la medida de aseguramiento - se resaltó lo siguiente: "A fin de que los derechos de las víctimas no queden desprotegidos por la solicitud reiterada de un imputado para que se revoque o sustituya la medida de aseguramiento restrictiva de la libertad, en cada caso concreto el juez de control de garantías deberá constatar que (i) efectivamente hayan desaparecido los requisitos que establece el artículo 308 de la Ley 906 de 2004, para la procedencia de la medida de aseguramiento; y (ii) que la supuesta desaparición de los requisitos esté sustentada en hechos nuevos de entidad suficiente para mostrar que indudablemente desaparecieron las circunstancias que justificaron la medida." 
CPP, ello solamente procede si existe medida de aseguramiento.

b) Cuando el fiscal no ordena la detención preventiva a pesar de que se reúnen los requisitos para hacerlo, los objetivos de la medida pueden verse anulados, ya sea por la no comparecencia del imputado en etapas subsiguientes, por la destrucción de elementos probatorios valiosos, o por la obstaculización (directa o indirecta) de la investigación. Sin duda todo ello afecta considerablemente los derechos a la verdad y a la justicia, de los cuales también es titular la parte civil, y que según fue indicado no son menos importantes que los derechos de contenido patrimonial.

c) En algunos eventos la gravedad de los hechos, sumada a la trascendencia de la decisión, demandan del Estado una actitud extremadamente rigurosa a fin de garantizar que el imputado no eluda el funcionamiento de la administración de justicia. Aquí la parte civil (con independencia de que sean víctimas o perjudicados), debe estar plenamente autorizada para cuestionar los yerros de las autoridades judiciales en las diferentes etapas del proceso.

d) Adicionalmente, tampoco puede desconocerse que la búsqueda de la verdad y la realización de la justicia son derechos íntimamente vinculados con el principio de legalidad, la observancia del debido proceso, la prevalencia del derecho sustancial y el derecho a la tutela judicial efectiva, en cabeza no sólo del sindicado o del Ministerio Público, sino también de la parte civil como sujeto procesal ${ }^{4}$.

Para la Corte los fines de la detención preventiva revisten significativa importancia para asegurar el pleno ejercicio de los derechos de la parte civil, razón por la cual debe ser tratada con criterios de igualdad frente a los mecanis-

\footnotetext{
C- 805 de 2002
}

mos jurídicos con que cuentan los demás sujetos procesales para controvertir las decisiones que llegaren a adoptarse al respecto. Si bien el control judicial de legalidad de la medida de aseguramiento, así como de las decisiones que afecten la propiedad, posesión, tenencia o custodia de bienes, constituye una garantía para el imputado y el Ministerio Público, de ella no puede estar excluida la parte civil, por cuanto también constituye una prerrogativa en su favor y frente a sus intereses. En consecuencia, la Corte declaró la constitucionalidad de la norma, pero en el entendido que el control de legalidad también puede ser solicitado por dicho sujeto procesal y el Ministerio Público, frente a la abstención de dictar la medida, toda vez que en ese sentido se configura una omisión legislativa contraria al ordenamiento superior.

En sentencia C-209 de 2007, destaca la Corte que la solicitud de medidas de aseguramiento o de protección ante el juez de control de garantías o ante el juez de conocimiento, según corresponda, tal como ha sido diseñada en la Ley 906 de 2004, sólo puede hacerla el fiscal. Esta fórmula pretende desarrollar el deber de protección de las víctimas establecido en el artículo 250, numeral 7 de la Carta, en concordancia con el literal b) del artículo 11 de la Ley 906 de 2004.

Para el Tribunal, la fórmula escogida por el legislador deja desprotegida a la víctima ante omisiones del fiscal, o ante circunstancias apremiantes que puedan surgir y frente a las cuales la víctima cuente con información de primera mano sobre hostigamientos o amenazas recibidas que hagan necesaria la imposición de la medida correspondiente, o sobre el incumplimiento de la medida impuesta, o la necesidad de cambiar la medida otorgada. Esto se aplica tanto a las medidas de aseguramiento como a las medidas de protección en sentido estricto.

Esta omisión excluye a la víctima como interviniente especial, que por estar en mejores condiciones para contar con información de primera mano sobre la necesidad de medidas de pro- 
tección o aseguramiento podría efectivamente solicitar al juez competente la medida correspondiente requerida.

Permitir la solicitud de medidas de aseguramiento o de protección directamente ante el juez competente por la víctima, sin mediación del fiscal, no genera una desigualdad de armas, no altera los rasgos fundamentales del sistema penal con tendencia acusatoria, ni implica una transformación del papel de interviniente especial que tiene la víctima dentro de este sistema procesal penal. Antes bien, asegura en mayor grado la adecuada protección de la vida, integridad, intimidad y seguridad de la víctima, de sus familiares y de los testigos a favor, así como de sus derechos a la verdad, a la justicia y a la reparación ${ }^{5}$.

Del anterior planteamiento para la Corte, esta omisión entraña el incumplimiento por parte del legislador del deber de configurar una intervención efectiva de la víctima en el proceso penal, en la medida que la deja desprotegida en circunstancias apremiantes o ante la omisión del fiscal en el cumplimiento de su deber de proteger a las víctimas y testigos de posibles hostigamientos o amenazas, y de solicitar las medidas necesarias para promover los fines previstos en el artículo 308 de la ley, los cuales guardan estrecha relación con los derechos de la víctima a la verdad y a la justicia.

Por lo anterior, el Tribunal declararó la exequibilidad del artículo 306, del artículo 316 y del artículo 342 de la Ley 906 de 2004, en el entendido que la víctima también puede acudir directamente ante el juez competente, ya sea el de control de garantías o el de conocimiento, según corresponda, a solicitar la medida respectiva.

C-209 de 2007. Para la Corte esta omisión genera además una desigualdad en la valoración de los derechos de la víctima, al dejarla desprotegida en circunstancias en las que deba acudirse urgentemente ante el juez competente para solicitar la adopción de una medida de protección o aseguramiento, o la modificación de la medida inicialmente otorgada.
Lo anterior no significa que el juez competente, al recibir de manera directa la solicitud de la víctima en el sentido que se imponga una medida de aseguramiento o una medida de protección específica, deba proceder a dictarla sin seguir el procedimiento señalado en las normas aplicables. Así, por ejemplo, en el caso de las medidas de aseguramiento debe previamente escuchar al fiscal, a la defensa y al Ministerio Público, como lo exige el propio artículo 306 acusado.

\section{FACULTAD DE LAS VÍCTIMAS PARA SOLICITAR LA PRÁCTICA DE PRUEBAS ANTICIPADAS}

En materia de facultades probatorias de la víctima, los artículos 284, 344, 356, 357, 358, 359, 371, 378, 391 y 395 de la Ley 906 de 2004, que tratan sobre las pruebas fueron demandadas alegando inconstitucionalidad de las mismas, con fundamento en que le impedían a la víctima participar en el debate probatorio y en el esclarecimiento de la verdad, al no permitir que solicitaran o controviertan los elementos materiales probatorios aportados por las partes en las distintas etapas de la actuación penal donde está previsto el debate probatorio.

La Corte Constitucional en sentencia C-209 de 2007, en estimó que efectivamente el artículo 284 , en su numeral 2, excluye a la víctima de los actores procesales que pueden solicitar la práctica de pruebas anticipadas para lograr el esclarecimiento de los hechos, de las circunstancias de su ocurrencia, la determinación de los responsables, de la magnitud de los daños sufridos y el esclarecimiento de la verdad.

Para el alto Tribunal, en el caso de la norma del 284 entraña un incumplimiento, por parte del legislador, del deber de configurar una verdadera intervención de la víctima en el proceso penal que le impide asegurar el derecho a la verdad y del derecho de las víctimas consagrado en el literal d) del artículo 11 de la Ley 906 de 2004. Por lo anterior, esta omisión resulta inconstitucional y en consecuencia, a la luz del cargo analizado, 
condicionó la constitucionalidad del numeral 2 del artículo 284 de la Ley 906 de 2004, en el entendido que la víctima también puede solicitar la práctica de pruebas anticipadas ante el juez de control de garantías ${ }^{6}$.

\section{FACULTAD PARA SOLICITAR EL DESCUBRIMIENTO DE LAS PRUEBAS}

En cuanto a las expresiones "la Fiscalía" y la "defensa" empleadas en el inciso segundo del artículo 344 de la Ley 906 de 2004, la Corte estimó que éstas no podian analizarse aisladamente sino que es necesario situarlas en el contexto de toda la disposición para comprender su sentido normativo ${ }^{7}$. Por ello, en el juicio se analizó sobre todo el artículo 344, por el cargo analizado. Efectuada dicha integración normativa estimó la Corte que: la norma excluye a la víctima de los actores procesales que pueden solicitar el descubrimiento de las pruebas ${ }^{8}$.

Para la Corte, esta omisión genera una desigualdad injustificada entre los distintos actores

\footnotetext{
C- 209 de 2007.

En este evento, la integración normativa procede bajo la primera hipótesis señalada en la sentencia C-320 de 1997, MP. Alejandro Martínez Caballero. Según esa sentencia, la integración de unidad normativa sólo procede de manera excepcional en tres eventos: (1) "cuando un ciudadano demanda una disposición que, individualmente, no tiene un contenido deóntico claro o unívoco, de manera que, para entenderla y aplicarla, resulta absolutamente imprescindible integrar su contenido normativo con el de otra disposición que no fue acusada." (2) "Cuando la disposición cuestionada se encuentra reproducida en otras normas del ordenamiento que no fueron demandadas." Y (3) "pese a no verificarse ninguna de las hipótesis anteriores, la norma demandada se encuentra intrínsecamente relacionada con otra disposición que, a primera vista, presenta serias dudas de constitucionalidad." Sobre el tema de integración normativa ver también, entre muchas otras, las sentencias C-357 de 1999, MP. José Gregorio Hernández Galindo; C-539 de 1999 MP. Eduardo Cifuentes Muñoz, C-781 de 2003, MP. Clara Inés Vargas Hernández; C-227 de 2004, MP. Manuel José Cepeda Espinosa; C-271 de 2003, MP. Rodrigo Escobar Gil; C-409 de 2004, MP. Alfredo Beltrán Sierra; C-538 de 2005, MP. Marco Gerardo Monroy Cabra; C-536 de 2006, MP. Humberto Antonio Sierra Porto.
}

$8 \quad$ C-209 de 2007. del proceso penal en las etapas previas al juicio; y al igual que en el caso de las solicitudes probatorias reguladas por el artículo 357 de la Ley 906 de 2004; impide a la víctima asegurar el esclarecimiento de la verdad en consecuencia, condicionó la exequibilidad del artículo 344 de la Ley 906 de 2004, en el entendido de que la víctima también puede solicitar el descubrimiento de un elemento material probatorio específico o de evidencia física específica.

\section{FACULTAD PARA HACER OBSERVACIONES SOBRE EL DESCUBRIMIENTO DE ELEMENTOS PROBATORIOS}

En este aparte de la sentencia el juicio recayó sobre el artículo 356. Al respecto, para la Corte la norma excluye a la víctima de los actores procesales que pueden participar en la audiencia preparatoria y hacer observaciones sobre el descubrimiento de elementos probatorios y la totalidad de las pruebas que se harán valer en la audiencia del juicio oral.

Consideró el Tribunal que no se observa una razón objetiva que justifique la exclusión de la víctima de esta facultad, como quiera que su participación en esta etapa previa al juicio oral, sólo tiene como finalidad el descubrimiento de elementos probatorios, pero no su contradicción o su práctica, por lo cual no conlleva una modificación de los rasgos estructurales del sistema penal, no altera la igualdad de armas, ni modifica la calidad de la víctima como interviniente especialmente protegido; Esta omisión, dijo la Corte, genera una desigualdad injustificada entre los distintos actores del proceso penal en la audiencia preparatoria, en consecuencia, declaró la exequibilidad del artículo 356 de la Ley 906 de 2004, en el entendido de que la víctima también puede hacer observaciones sobre el descubrimiento de elementos probatorios y de la totalidad de las pruebas que se harán valer en la audiencia del juicio oral ${ }^{9}$.

Ibidem 


\section{FACULTAD PARA SOLICITAR LA EXHIBICIÓN DE LOS ELEMENTOS MATERIALES PROBATORIOS}

En relación con la expresión "a solicitud de las partes" usada en el artículo 358 de la Ley 906 de 2004, la Corte considera que la norma excluye a la víctima de los actores procesales que pueden solicitar la exhibición de los elementos materiales probatorios y evidencia física, con el fin de conocerlos y estudiarlos.

Esta omisión, para los magistrados, genera una desigualdad injustificada entre los distintos actores del proceso penal en la audiencia preparatoria y en consecuencia, declaró la constitucionalidad del artículo 358 de la Ley 906 de 2004, en el entendido que la víctima también puede hacer dicha solicitud ${ }^{10}$.

\section{FACULTAD PARA SOLICITAR LA EXCLUSIÓN, EL RECHAZO O LA INADMISIBILIDAD DE LOS MEDIOS DE PRUEBA}

En relación con la expresión "las partes y el Ministerio público" contenida en el inciso primero del artículo 359 de la Ley 906 de 2004 se razono que la norma no incluye a la víctima dentro de los actores procesales que pueden solicitar la exclusión, el rechazo o la inadmisibilidad de los medios de prueba, en consecuencia, estimó la constitucionalidad del inciso primero del artículo 359 de la Ley 906 de 2004, en el entendido que la víctima también puede solicitar la exclusión, el rechazo o la inadmisibilidad de los medios de prueba ${ }^{11}$.

\section{FACULTADES DE LA VÍCTIMA EN RELACIÓN CON LA APLICACIÓN DEL PRINCIPIO DE OPORTUNIDAD}

Siguiendo las orientaciones del artículo 250 de la Carta, la Fiscalía General de la Nación, por regla general y en virtud del principio de lega- lidad, está obligada a ejercer la acción penal, el mismo artículo 250 superior permitió que excepcionalmente pudiera renunciar a la persecución penal en aplicación del principio de oportunidad.

En la sentencia C-873 de $2003,{ }^{12}$ se señala como uno de los rasgos característicos del sistema penal con tendencia acusatoria instaurado mediante el Acto Legislativo No. 03 de 2002 y desarrollado en la Ley 906 de 2004, el poder de disposición del proceso penal en los siguientes términos:

"El poder de disposición del proceso también fue modificado en cuanto a su alcance por el constituyente derivado de 2002, ya que se consagró a nivel constitucional el principio de oportunidad, por oposición al principio de legalidad. El principio de oportunidad ha sido reconocido en múltiples ordenamientos penales del mundo, y se basa en el postulado de que la acusación penal requiere no sólo que exista suficiente mérito para acusar por razones fácticas y jurídicas, sino que no existan razones de oportunidad para archivar el proceso, esto es, razones válidas por las cuales el Estado puede legítimamente optar por no perseguir penalmente una determinada conducta, en los "casos que establezca la ley" y "dentro del marco de la política criminal del Estado" ${ }^{13}$. Se trata de una previsión constitucional de las hipótesis en las cuales procede archivar la investigación, las cuales serán reguladas en detalle por la ley. El Legislador también deberá regular el alcance del control judicial de lega-

Sentencia C-873 de 2003, MP. Manuel José Cepeda Espinosa, con salvamento de voto del magistrado Jaime Araujo Rentaría. Salvamento y aclaración de voto Magistrados Alfredo Beltrán Sierra y Álvaro Tafur Galvis.

13 La Corte Constitucional aceptó el principio de oportunidad tratándose de juicios ante el Congreso. Ver sentencia SU-062 de 2001, MP. Eduardo Montealegre Lynett, en la cual se expresó: "es posible que el Congreso se abstenga de formular acusación por razones de conveniencia, en aquellos casos en que la ponderación de bienes jurídicos constitucionales le permita concluir que resulta más benéfico para la estabilidad institucional una exoneración de responsabilidad, que un juicio de consecuencias imprevisibles.(...)". 
lidad previsto por el Acto Legislativo para las actuaciones en las que se aplique este principio, lo cual es especialmente relevante para proteger los derechos de las víctimas a la justicia, la verdad y la reparación ${ }^{14}$.

En la sentencia C-673 de $2005,{ }^{15}$ la Corte describió las características regladas y excepcionales del principio de oportunidad en lo siguientes términos:

“(...), en el Acto Legislativo 03 de 2002 se dispuso que la Fiscalía General de la Nación está obligada a adelantar el ejercicio de la acción penal de los hechos que revistan las características de un delito, que lleguen a su conocimiento por una de las siguientes vías: denuncia, petición especial, querella o de oficio, "siempre y cuando medien suficientes motivos y circunstancias fácticas que indiquen la posible comisión del mismo". En consecuencia, la Fiscalía no podrá suspender, interrumpir o renunciar al ejercicio de la acción penal, "salvo en los casos que establezca la ley para la aplicación del principio de oportunidad regulado dentro del marco de la política criminal del Estado, el cual estará sometido al control de legalidad por parte del juez que ejerza las funciones de control de garantías".

"En tal sentido, el principio de oportunidad presenta las siguientes características (i) es una figura de aplicación excepcional mediante la cual se le permite al fiscal suspender, interrumpir o renunciar al ejercicio de la acción penal; (ii) las causales de aplicación del principio de oportunidad deben ser establecidas por el legislador de manera clara e inequívoca; (iii) debe ser aplicado en el marco de la política criminal del Estado; y, (iv) su ejercicio estará sometido al control de legalidad por parte del juez que ejerza las funciones de control de garantías."

14 Ver sentencia C-228 de 2002, MM.PP. Manuel José Cepeda Espinosa y Eduardo Montealegre Lynett.

15 Sentencia C-673 de 2005, MP. Clara Inés Vargas Hernández, Salvamento de Voto del Magistrado Rodrigo Escobar Gil.
Más recientemente, en la sentencia C-095 de $2007,{ }^{16}$ la Corte se pronunció sobre la constitucionalidad de algunas de las causales de aplicación del principio de oportunidad cuestionadas porque supuestamente adolecían de falta de claridad y precisión. La Corte dijo lo siguiente sobre la garantía de los derechos de las víctimas:

"El principio de oportunidad no implica el desconocimiento de los derechos de las víctimas. En adición a lo anterior, la Corte estima necesario poner de manifiesto que la aplicación del principio de oportunidad previsto en la Constitución debe ser compatible con el respeto a los derechos de las víctimas de las conductas delictivas. Lo anterior se deduce con claridad del mismo texto del Acto Legislativo 03 de 2002, que asigna al Fiscal, a quien simultáneamente corresponde aplicar el principio de oportunidad, la misión de "velar por la protección de las víctimas" (C.P. Artículo 250, numeral 7) y también "Solicitar al juez que ejerza las funciones de control de garantías las medidas necesarias que aseguren... la protección de la comunidad, en especial, de las víctimas." (C.P. Artículo 250, numeral 1).

La Corte, en sentencia C-209 de 2007, estimó que negar a la víctima la posibilidad de impugnar la decisión del juez de control de garantías sobre la aplicación del principio de oportunidad vulnera sus derechos. Así, dada la trascendencia que tiene la aplicación del principio de oportunidad en los derechos de las víctimas del

16 Sentencia C-097 de 2007, MP. Marco Gerardo Monroy Cabra, Salvamento de Voto de los Magistrados Jaime Araujo Rentería, y Clara Inés Vargas Hernández y Salvamento Parcial de Voto del Magistrado Humberto Antonio Sierra Porto. En esa oportunidad la Corte resolvió lo siguiente: Primero.- Declarar exequibles los numerales 4,5,6,9,11,12 y 15 del artículo 324 de la Ley 906 de 2004, por los cargos estudiados en la presente sentencia. Segundo.- Declarar exequible la expresión "En los casos previstos en los numerales 15 (...)" contenida en el parágrafo $1^{\circ}$ del artículo 324 de la Ley 906 de 2004, por el cargo estudiado en la presente sentencia. Tercero.- Declarar exequible el parágrafo $3^{\circ}$ de la Ley 906 de 2004, por los cargos estudiados en esta sentencia, salvó la expresión "de acuerdo con lo dispuesto en el estatuto de Roma", que se declara inexequible. 
delito, impedir que éstas puedan impugnar la renuncia del Estado a la persecución penal, sí deja desprotegidos sus derechos a la verdad, a la justicia y a la reparación integral. Si bien la satisfacción de los derechos de la víctima no sólo se logra a través de una condena, la efectividad de esos derechos sí depende de que la víctima tenga la oportunidad de impugnar las decisiones fundamentales que afectan sus derechos. ${ }^{17}$ Por lo tanto, impedir la impugnación de la decisión del juez de garantías en este evento resulta incompatible con la Constitución.

Con fundamento en lo anteriormente expuesto al Corte declaró la inexequibilidad de la expresión "y contra esa determinación no cabe recurso alguno", empleada en el artículo 327 de la Ley 906 de 2004. La correspondiente apelación se hará, en lo aplicable, de conformidad con lo previsto en los artículos 176, 177, 178 y 179 de la Ley 906 de $2004^{18}$.

\section{FACULTAD DE LA VÍCTIMA EN RELACIÓN CON LA PRECLUSIÓN DEL PROCESO}

La preclusión de la investigación penal se presenta cuando el fiscal considera que no existe mérito para acusar (artículo 331, Ley 906 de 2004), lo cual ocurre, según el artículo 332 de la Ley 906 de 2004, cuando: existe imposibilidad de iniciar o continuar el ejercicio de la acción penal; exista una causal de exclusión de responsabilidad penal, el hecho investigado no haya ocurrido; o sea atípico; el imputado no haya intervenido en el hecho investigado; sea imposible desvirtuar la presunción de inocencia; o hayan vencido los términos previstos en los artículos 175 y 294 de la Ley 906 de 2004.

Según el trámite previsto en el artículo 333 de la Ley 906 de 2004, la solicitud de preclusión la hace el fiscal ante el juez de conocimiento, en una audiencia preliminar que tiene lugar a par-

\footnotetext{
17 Numerales 6 y 7, Art. 250 CP, y literales f y g del artículo 11 de la Ley 906 de 2004

18 Sentencia C-209 de 2007
}

tir de la formulación de la imputación, antes del juicio oral. En dicha audiencia participan el fiscal, la víctima, el agente del Ministerio Público, y el defensor del imputado; el fiscal expone su solicitud e indica los elementos materiales probatorios que lo llevaron a concluir que no existe mérito para acusar. Luego de esta intervención, la víctima, el agente del Ministerio Público, y el defensor del imputado, pueden oponerse a la solicitud del fiscal. Sin embargo, tal como está previsto, no pueden solicitar ni practicar pruebas. Culminado el debate, el juez motivará oralmente su decisión, para lo cual puede suspender la audiencia por una hora, a fin de preparar su decisión.

Si la decisión es decretar la preclusión, cesa la persecución penal en contra del imputado por esos hechos, y se revocan las medidas cautelares que se hayan impuesto. Tal decisión tiene efectos de cosa juzgada. Si la decisión es rechazar la preclusión, las diligencias vuelven a la fiscalía. Esa decisión se adopta mediante sentencia, y contra ella, según lo establece el artículo 177 de la Ley 906 de 2004, cabe la apelación.

Como sucede con la decisión de archivo de las diligencias, regulada en el artículo 79 de la Ley 906 de 2004, y examinada por la Corte en la sentencia C-1154 de 2005, la decisión de preclusión tiene incidencia directa sobre los derechos de las víctimas, en la medida en que afecta el esclarecimiento de la verdad y la obtención de justicia en el caso concreto.

En sentencia C-209 de 2007, observó la Corte, que cuando se decreta la preclusión, esta decisión tiene como efecto cesar la persecución penal contra el imputado respecto de los hechos objeto de investigación, y tiene efectos de cosa juzgada; no permitir a la víctima controvertir adecuadamente la solicitud del fiscal puede conducir a una afectación alta de sus derechos, e incluso, a la impunidad. En efecto, dado que al decretarse la preclusión, la víctima no puede solicitar la reanudación de la investigación, ni aportar nuevos elementos probatorios que permitan reabrir la investigación contra el imputa- 
do favorecido con la preclusión, resulta esencial adelantar un control adecuado de las acciones y omisiones del fiscal, y controvertir de manera efectiva de sus decisiones. Por ello, el trámite de la solicitud de preclusión debe estar rodeado de las mayores garantías. En consecuencia, el Tribunal, declaró exequible el artículo 333 en el entendido que las víctimas pueden allegar o solicitar elementos materiales probatorios y evidencia física para oponerse a la petición de preclusión del fiscal ${ }^{19}$.

\section{LAS FACULTADES DE LA VÍCTIMA EN LA FORMULACIÓN DE LA ACUSA- CIÓN EN LA ETAPA DEL JUICIO ORAL}

De conformidad con el Acto Legislativo No. 3 de 2002 al proceso penal, el poder de acusación corresponde a la Fiscalía. ${ }^{20}$ Siguiendo ese lineamiento, la Ley 906 de 2004 estableció en el artículo 114 como atribución expresa de la Fiscalía General de la Nación: "Investigar y acusar a los presuntos responsables de haber cometido un delito," y el artículo 116, en su numeral primero, señaló como atribución especial del Fiscal General de la Nación "investigar y acusar, si hubiere lugar, a los servidores públicos que gocen de fuero constitucional, con las excepciones previstas en la Constitución". No obstante, la radicación de la acusación en cabeza de la Fiscalía, no excluye la posibilidad de que las víctimas contribuyan a la construcción del caso que presente el fiscal ante el juez de conocimiento. Los artículos mencionados, se

19 Sentencia C- 209 de 2007.

20 Sentencia C-873 de 2003, MP. Manuel José Cepeda Espinosa, con salvamento de voto del magistrado Jaime Araujo Rentaría. Salvamento y aclaración de voto Magistrados Alfredo Beltrán Sierra y Álvaro Tafur Galvis, en donde la Corte describió los rasgos estructurales del procedimiento penal introducido por el Acto Legislativo 03 de 2002. En relación con el poder de acusación, la Corte expresó lo siguiente: "(b) los poderes atribuidos a quienes participan en el proceso fueron objeto de una regulación constitucional expresa que modificó su alcance en varios aspectos: (...) (iv) El poder de acusación se mantiene en cabeza de la Fiscalía; no así el de declarar precluida la investigación, que ahora corresponde al juez de conocimiento de la causa, a solicitud de la Fiscalía (art. 250-5, modificado)." refieren al contenido del documento de acusación (Artículo 337, Ley 906 de 2004), al trámite en la audiencia de formulación de acusación (Artículo 339, Ley 906 de 2004), y a la presentación de la teoría del caso en el juicio oral (Artículo 371, Ley 906 de 2004). En relación con ellos, se tiene que el artículo 337, así como las expresiones "a las demás partes", "la Fiscalía, el Ministerio Público y defensa" contenidas en el inciso primero del artículo 339 y 371 de la Ley 906 de 2004, al excluir a la víctima de la posibilidad de participar en la definición de la teoría del caso y en la formulación de la acusación, cercena sus derechos a la verdad, a la justicia y a la reparación.

Según el artículo 336 de la Ley 906 de 2004, cuando de los elementos materiales probatorios, y la evidencia física e información legalmente obtenida en la etapa de investigación permitan afirmar con "probabilidad de verdad", que la conducta delictiva existió y que el imputado es el autor o partícipe, el fiscal presenta ante el juez de conocimiento un escrito de acusación, en el cual, entre otras cosas, se individualiza a los acusados, se hace una relación sucinta de los hechos, y se efectúa el descubrimiento de las pruebas, para mencionar sólo algunos de los requisitos de la acusación (artículo 337, Ley 906 de 2004). Copia de este documento se entrega al acusado, al Ministerio Público, y a las víctimas "con fines únicos de información."

Posteriormente, el juez de conocimiento fija la fecha y hora para la audiencia de formulación de acusación (artículo 338, Ley 906 de 2004). En el trámite de la audiencia de formulación de acusación, se señala de manera expresa y taxativa quiénes pueden intervenir: las partes procesales, la Fiscalía y la defensa, y el Ministerio Público. En la demanda que dio origen a la sentencia C-209 de 2007, el actor, expresa que, en este procedimiento, la víctima no fue incluida dentro de los actores procesales que participan en dicha audiencia ni está prevista su intervención siquiera incidental en esta etapa, con lo cual se confirma que el traslado del escrito de acusación que se le hace a la víctima en 
el artículo 337 tiene un carácter eminentemente informativo, y no le permite ningún tipo de actuación para controlar la adecuación típica, o el descubrimiento de las pruebas que hará valer el fiscal en la etapa del juicio oral.

Según lo que señala el artículo 339 de la Ley 906 de 2004, la finalidad de la intervención de los actores procesales autorizados a participar en la audiencia de formulación de acusación, es la de ejercer un control de ésta a través de dos medios: La formulación de observaciones al escrito de acusación, a fin de que el fiscal lo aclare, corrija o adicione, y además la manifestación oral de causales de incompetencia, impedimentos, recusaciones, o nulidades que pudiera haber. La exclusión de la víctima en esta etapa le impide fijar su posición frente a la acusación, y, en especial, actuar de manera que se garanticen efectivamente sus derechos a la verdad, la justicia y la reparación en un momento crítico del proceso.

Estimó la Corte, que en este caso, tal como fue diseñado por el legislador, la víctima no tiene ninguna posibilidad de fijar su posición sobre la acusación, ni sobre la adecuación típica o el descubrimiento de pruebas que hará valer el fiscal en la etapa del juicio oral, mientras que las partes e intervinientes como el Ministerio Público, sí tienen esa posibilidad. Dado que no necesariamente existe coincidencia de intereses entre la fiscalía y la víctima, o entre la víctima y el Ministerio Público en la etapa de la definición de la acusación, los derechos de las víctimas a la verdad, la justicia y la reparación integral pueden resultar desprotegidos en esta etapa crucial del proceso penal. Teniendo en cuenta la trascendencia de la participación de la víctima en esta etapa de la actuación penal, es claro que la omisión del legislador pone en riesgo la efectividad de los derechos de la víctima y por ello resulta inconstitucional ${ }^{21}$.

${ }_{21}$ Sentencia C-209 de 2007. Dijo la Corte: "Si bien es cierto que la Constitución radicó la facultad de acusación en la Fiscalía, no se ve una razón objetiva y suficiente que justifique la exclusión completa de la víctima en la fijación de su posición frente a la acusación, puesto que la intervención de la víctima no supone una modi-
En consecuencia el Tribunal declaró la inexequibilidad de la expresión "con fines únicos de información" contenida en el inciso final del artículo 337 de la Ley 906 de 2004. Igualmente, declaró la exequibilidad del artículo 339 en el entendido que la víctima también puede intervenir en la audiencia de formulación de acusación para elevar observaciones al escrito de acusación o manifestarse sobre posibles causales de incompetencia, recusaciones, impedimentos o nulidades.

\section{LIMITACIONES DE PARTICIPACIÓN DE LAS VÍCTIMAS EN EL JUICIO ORAL}

Si bien, no nos vamos a referir a los derechos y facultades de las víctimas, en este aparte, es preciso establecer que las facultades de intervenir la víctima en el juicio oral como segundo acusador están limitadas, de conformidad con el artículo 378, 391 y 395 de la Ley 906 de 2004, donde excluyen a la víctima de los actores procesales que pueden controvertir los medios de prueba, los elementos materiales probatorios y la evidencia física presentados en la etapa del juicio oral, así como interrogar al testigo y oponerse a las preguntas que se planteen en el juicio oral.

Para la Corte, existe una razón objetiva que justifica la limitación de los derechos de la víctima,

ficación de las características estructurales del sistema penal con tendencia acusatoria, ni una transformación de la calidad de interviniente especialmente protegido que tiene la víctima. La fijación de su posición no afecta la autonomía del Fiscal para acusar, ni mucho menos lo desplaza en el ejercicio de las facultades que le son propias. Esta exclusión de las víctimas genera una desigualdad injustificada frente a los demás actores del proceso que desprotege sus derechos. Por ello, tanto la limitación que hace el artículo 337, de restringir la finalidad de la entrega del escrito de acusación "con fines únicos de información", como la omisión de incluir a la víctima (o a su apoderado) en la audiencia de formulación de acusación para que haga observaciones, solicite su aclaración o corrección o para que se manifieste sobre posibles causales de incompetencia, recusaciones, impedimentos o nulidades, significa un incumplimiento de los deberes constitucionales que tiene el legislador en la protección de los derechos de la víctima". 
como quiera que su participación directa en el juicio oral implica una modificación de los rasgos estructurales del sistema penal acusatorio que comporta una alteración sustancial de la igualdad de armas y convierte a la víctima en un segundo acusador o contradictor en desmedro de la dimensión adversarial de dicho proceso.

Esta omisión no genera una desigualdad injustificada entre los distintos actores del proceso penal, sino que busca evitar que la defensa quede en una situación de desventaja en el juicio oral dados sus rasgos esenciales definidos por el propio constituyente.

Para la Corte, esta limitación, tampoco supone un incumplimiento por parte del legislador del deber de configurar una intervención efectiva de la víctima en el proceso penal, como quiera que la posibilidad de que la víctima (o su apoderado) intervenga para controvertir los medios de prueba, los elementos materiales probatorios y la evidencia física presentados en la etapa del juicio oral, así como interrogar al testigo y oponerse a las preguntas que se planteen en el juicio oral, se ejercerá a través del fiscal con base en la actividad propia y en la de las víctimas en las etapas previas del proceso, según los derechos que le han sido reconocidos en esta sentencia y en la ley. En efecto, a lo largo del proceso penal, en las etapas previas, la víctima ha podido participar como interviniente especial en la construcción del caso para defender sus derechos, de tal forma que en el juicio mismo éstos se proyectarán mediante la actividad fiscal.

No obstante, la víctima, a través de su abogado, podrá ejercer sus derechos en la etapa del juicio sin convertirse en una parte que pueda presentar y defender su propio caso al margen del Fiscal. El conductor para culminar en esta etapa final del proceso el ejercicio de sus derechos es el fiscal, quien debe oír al abogado de la víctima. Así, por ejemplo, éste podrá aportar a la Fiscalía observaciones para facilitar la contradicción de los elementos probatorios, antes y durante el juicio oral, pero solo el fiscal tendrá voz en la audiencia en aquellos aspectos regu- lados por las normas acusadas. En el evento de que la víctima y su abogado estén en desacuerdo con la sentencia podrán ejercer el derecho de impugnarla, de conformidad con el artículo 177 de la Ley 906 de 2004.

Cabe agregar que en el sistema colombiano el Ministerio Público es un interviniente sui generis que también puede abogar por los derechos de todos, incluidas las víctimas en dicha etapa, sin sustituir ni al Fiscal ni a la defensa" ${ }^{22}$.

\section{LIMITACIÓN DE LA INTERVENCIÓN DE LAS VÍCTIMAS EN LA PRESENTA- CIÓN DE LA TEORÍA DEL CASO}

Según el artículo 371, en la etapa del juicio oral, el fiscal presentará la teoría del caso, y lo mismo hará la defensa, pero dicho artículo no prevé que la víctima tenga participación alguna en este momento del juicio oral. No obstante, tal como se señaló al rechazar la posibilidad de que la víctima interviniera directamente en la audiencia del juicio oral para controvertir pruebas o interrogar a los testigos, aquí también está justificada la limitación de sus derechos. Dado el carácter adversarial de esta etapa del juicio penal y la necesidad de proteger la igualdad de armas, no puede la víctima participar de manera autónoma y al margen de la actuación del fiscal.

Advierte la Corte que el artículo 443 de la Ley 906 de 2004 prevé la posibilidad de que el abogado de las víctimas intervenga para hacer alegatos finales al concluir el juicio. Esta participación del abogado de la víctima no introduce un desbalance en el juicio ni le resta su dinámica adversarial puesto que ella se presenta al final de esta etapa, con miras precisamente a que la voz de las víctimas se escuche antes de concluir esta etapa del proceso.

Para la Corte, dado que en las etapas previas del proceso penal la víctima ha tenido la oportunidad de participar como interviniente especial para contribuir en la construcción del expedien-

$22 \quad$ C- 209 de 2007. 
te por parte del fiscal, en la etapa del juicio oral la víctima, a través de su abogado, podrá ejercer sus derechos sin convertirse en una parte que pueda presentar y defender su propia teoría al margen del Fiscal, y en esa medida, el ejercicio de sus derechos se materializará a través del fiscal, quien debe oír al abogado de la víctima.

\section{CONCLUSIONES}

El redescubrimiento de la víctima es un hecho que se ve reflejado en las legislaciones modernas, en la nuestra con la ley 906 de 2004, es considerado un sujeto procesal, situación esta que quedo esclarecida y ratificada con las sentencias C-454 de 2006, C-228 de 2002, C-209 de 2007, entre otras, y frente a la cual se precisa las facultades y derechos de las victimas en el proceso penal acusatorio.

En consecuencia, se puede afirmar sin temor a equivocarnos que una de las aspiraciones del legislador colombiano con la Ley 906, ha sido el poder implantar los derechos de la víctima en el proceso penal, dándole una amplia participación como sujeto procesal, como participante activo y con facultades para intervenir en la solución del conflicto originado con el delito y este anhelo se fue consolidando a través de las jurisprudencia de la Corte Constitucional en sus diferentes sentencias a partir de la vigencia del nuevos sistema procesal acusatorio.

\section{BIBLIOGRAFÍA}

ALONSO RIMO, Alberto. Víctima y sistema penal: Las infracciones no perseguibles de oficio y el perdón del ofendido. Editorial Tirant lo Banch. Valencia, 2002.
BERISTAIN IPIÑA, Antonio. Criminología y Victimología. Alternativas Re-creadoras al Delito. Leyer, Bogotá, 1998.

--- Criminología, Victimología y Cárceles. Tomo I. Pontificia Universidad Javeriana. Facultad de Ciencias Jurídicas. Colección Profesores 22, Bogotá, 1996.

BUSTOS RAMÍREZ, Juan y Larrauri Elena. Victimología: Presente y futuro. Temis. Bogotá, 1993.

GARCÍA-PABLOS, Antonio. Tratado de Criminología. Editorial Tirant lo Banch. Valencia, 1999.

--- La resocialización de la víctima: víctima, sistema legal y política criminal. Criminología y Derecho Penal al Servicio de la Persona. Libro - Homenaje al profesor Antonio Beristain. Donostia - San Sebastián, 1989.

JAKOBS, GÜNTHER. Derecho Penal. Parte General. Fundamentos y teoría de la imputación. Marcial Pons, Madrid, 1995. Traducción de Joaquín Cuello Contreras y Jose Luis Serrano González de Murillo.

LANDROVE DIAZ, Gerardo. Victimología. Tirant lo Blanch. Valencia, 1990.

MESSUTI, Ana. El tiempo como pena y otros escritos. Pontificia Universidad Javeriana. Facultad de Ciencias Jurídicas. Criminología y Victimología 2. Bogotá, 1998.

MIR PUIG, Santiago. Derecho Penal, Parte General. 4ª Edición. Barcelona, 1996. 